\title{
EFFECT OF NONGRAY THERMAL RADIATION ON LAMINAR FORCED CONVECTION OVER A HEATED HORIZONTAL PLATE
}

\author{
HERBERT A. LORD and VEDAT S. ARPACI \\ University of Michigan, Ann Arbor, Michigan 48104, U.S.A.
}

(Received 31 October 1968 and in revised form 17 November 1969)

\begin{abstract}
The interaction of radiation with convection in an absorbing and emitting boundary layer is investigated by means of the integral method. Laminar flow of a nongray constant fluid over a gray, diffuse, isothermal flat plate is considered for small temperature differences. Second order analyses including the explicit effect of radiation on temperature profiles are carried out for optically thin and optically thick boundary layers. Closed form solutions are obtained for the Nusselt number, and plots are presented to illustrate the effect of optical thickness on temperature profiles and the Nusselt number.
\end{abstract}

\section{$B_{\infty}, \quad$ Boltzmann number,} $\rho U_{\infty} C_{p} /(4+m) \sigma T_{w}^{3}$

$B_{v}, \quad$ Planck function;

$C_{p}, \quad$ specific heat;

$C_{1}, C_{2}$, integration constants;

$E_{n}$, integro-exponential function of order $n$,

$$
E_{n}(t) \equiv \int_{0}^{1} \mu^{n-2} \mathrm{e}-{ }^{t / \mu} \mathrm{d} \mu
$$

h, heat-transfer coefficient;

$k$, thermal conductivity;

$k_{e}, \quad$ effective thermal conductivity, $\left(1+\frac{4}{3} \mathscr{P}_{w}\right) k$

$m$, exponent in temperature dependence of Planck mean absorption coefficient, equation (12);

$n$, exponent in temperature dependence of Rosseland mean absorption coefficient, equation (53);

$N_{x}, \quad$ local Nusselt number, $h x / k$;

$P, \quad$ Prandtl number, $\mu C_{p} / k$;

$P_{e}, \quad$ effective Prandtl number, $\mu C_{p} / k_{e}$;

$\mathscr{P}_{w}, \quad$ Planck number, $\alpha_{0}^{2} k /(4+m) \alpha_{p}\left(T_{w}\right) \sigma T_{w}^{3}$ $q$, heat flux;

$q^{R}, q^{C}, \quad$ radiant and conductive heat fluxes, respectively;

$R_{x}, \quad$ local Reynolds number, $\rho U_{\infty} x / \mu$;

$T, \quad$ temperature;

$T_{1}, T_{2}$, temperatures in regions 1 and 2 , respectively;

$u, \quad$ longitudinal velocity;

$U_{\infty}, \quad$ free stream velocity;

$v, \quad$ transverse velocity component;

$x$, distance along plate from leading edge;

$y, \quad$ transversal distance from plate;

$\alpha_{v}, \quad$ monochromatic volumetric absorption coefficient;

$\alpha_{p}, \quad$ Planck mean absorption coefficient;

$\alpha_{M}$, modified Planck mean absorption coefficient;

$\alpha_{R}, \quad$ Rosseland mean absorption coefficient;

$\alpha_{0}$, mean absorption coefficient of absorbing bands,

$\beta, \quad$ temperature jump parameter, $\left(1 / \tau_{0}\right) \ln \left[\left(3 \mathscr{P}_{w}+4\right) /\left(3 \mathscr{P}_{w}+2 \epsilon\right)\right] ;$

$\delta$, hydrodynamic boundary-layer thickness; 
$\Delta, \quad$ conduction boundary-layer thickness;

$\epsilon, \quad$ wall emissivity;

$\theta, \quad$ dimensionless temperature, $T / T_{w}$;

$\mu, \quad$ gas viscosity;

$v, \quad$ frequency;

$\xi$, ratio of boundary layer thicknesses, $\delta / \Delta$

$\rho, \quad$ gas density;

$\sigma$, Stefan-Boltzmann constant ;

$\tau_{0}, \quad$ optical thickness of conduction boundary layer, $\alpha_{0} \Delta$.

\section{INTRODUCTION}

RECENT advances in heat transfer research now provide the boundary layer studies including radiation effects demanded by the increased importance of space technology. Among many problems, heat transfer to an absorbing medium in a laminar boundary layer over an isothermal black plate has been investigated by a number of authors. Cess [1] studied the optically thin boundary layer in a constant property gray and simplified non-gray gas; a solution valid outside the conduction boundary layer was obtained in terms of a much thicker radiation boundary layer, and another solution was found inside the conduction layer; numerical methods were used. Oliver and McFadden [2] investigated a gray perfect gas having temperature dependent viscosity and thermal conductivity flowing over a black surface; the solution procedure was numerical and iterative, and was restricted to fairly small optical thicknesses.

Zamuraev [3] studied thin and intermediate boundary layers over a black plate, accounting for radiant flux at the outer edge of the conduction boundary layer; a numerical solution was obtained by the finite difference method. Viskanta and Grosh [4] investigated an optically thick gray gas flowing over a black wedge; an effective thermal conductivity was defined to include both conduction and radiation, and the wall effect was accounted for by assuming a step change in effective conductivity near the wall; the solution was obtained by numerical integration.

Novotny and Yang [5] considered a gray, constant property thick gas using the method of matched asymptotic expansions; it was concluded that the use of the thick gas approximation throughout the entire flow field gives the correct result for the total heat flux but an incorrect value for the temperature gradient at the wall, and consequently for the individual conductive and radiant fluxes.

Taitel and Hartnett [6] studied the case of specified heat flux, obtaining an approximate solution for the optically thin boundary layer, a similarity solution for the optically thick limit, and a finite difference solution for intermediate thicknesses; the finite difference solution, however, could not be made to approach the thick gas solution for large optical thicknesses, as the system of equations became unstable. Arpaci [7] applied the integral method to natural convection from a heated vertical plate, and in the same work developed a thick gas model including the wall effect; the temperature profiles employed were those proposed by Squire for the same problem in the absence of radiation (see e.g. Howarth [8]), and thus the effect of radiation was confined to the modification of the boundary layer thickness.

In this paper the integral method is applied to laminar forced boundary layer flow of a nongray, constant property gas over a gray, diffuse, isothermal flat plate. Recalling that first order profiles give unsatisfactory quantitative results for forced convective boundary layers, second order profiles are considered. Radiation explicitly affects the shape of the temperature profiles selected as well as the boundary-layer thickness. The present study offers two major advantages over those used previously for forced convection. First, closed form solutions are obtained for both thin and thick boundary layers, and second, a first order departure from the limiting thick gas solution is considered, including the effect of gray walls. Therefore it becomes possible, by the use of the thin and modified thick gas 
approximations, to interpret the gas domains from transport to opaque and from cold to hot.

\section{FORMULATION}

Consider a constant property fluid flowing over an infinite flat plate. The flow is laminar, the wall temperature $T_{w}$ is maintained constant, and at points far from the plate the fluid velocity and temperature have the uniform values $U_{\infty}$ and $T_{\infty}$, respectively. Assuming that radiation and conduction in the $x$ (longitudinal) direction are negligible compared to convection, the integral formulation of the problem is given by

$$
\begin{aligned}
& \rho \frac{\mathrm{d}}{\mathrm{d} x} \int_{0}^{\infty}\left(U_{\infty}-u\right) u \mathrm{~d} y=\mu\left(\frac{\partial u}{\partial y}\right)_{w}, \\
& \rho C_{p} \frac{\mathrm{d}}{\mathrm{d} x} \int_{0}^{\infty}\left(T-T_{\infty}\right) u \mathrm{~d} y=\left.q\right|_{w} .
\end{aligned}
$$

Neglecting the small contributions of radiation to pressure and internal energy, its effect is taken into account in the heat flux expression,

$$
q=q^{c}+q^{R},
$$

where

$$
q^{c}=-k \frac{\partial T}{\partial y},
$$

and for a semi-infinite expanse of a nonscattering gas having a temperature independent monochromatic absorption coefficient $\alpha_{v}$ bounded by a gray diffuse wall with emissivity $\epsilon$ and reflectivity $\rho_{w}=1-\epsilon$,

$$
\begin{aligned}
q^{R}(y) & =2 \int_{0}^{\infty}\left\{\epsilon B_{v, w} E_{3}\left(\alpha_{v} y\right)\right. \\
& +2 \rho_{w} E_{3}\left(\alpha_{v} y\right) \alpha_{v} \int_{0}^{\infty} B_{v}\left(y^{\prime}\right) E_{2}\left(\alpha_{v} y^{\prime}\right) \mathrm{d} y^{\prime} \\
& +\alpha_{v} \int_{0}^{y} B_{v}\left(y^{\prime}\right) E_{2}\left[\alpha_{v}\left(y-y^{\prime}\right)\right] \mathrm{d} y^{\prime} \\
& \left.-\alpha_{v} \int_{y}^{\infty} B_{v}\left(y^{\prime}\right) E_{2}\left[\alpha_{v}\left(y^{\prime}-y\right)\right] \mathrm{d} y^{\prime}\right\} \mathrm{d} v,
\end{aligned}
$$

$$
\begin{aligned}
\frac{\partial q^{R}}{\partial y} & =2 \int_{0}^{\infty}\left\{2 \alpha_{v} B_{v}(y)-\alpha_{v}\left[\epsilon B_{v, w} E_{2}\left(\alpha_{v} y\right)\right.\right. \\
& -2 \rho_{w} \alpha_{v} E_{2}\left(\alpha_{v} y\right) \int_{0}^{\infty} B_{v}\left(y^{\prime}\right) E_{2}\left(\alpha_{v} y^{\prime}\right) \mathrm{d} y^{\prime} \\
& -\alpha_{v} \int_{0}^{v} B_{v}\left(y^{\prime}\right) E_{1}\left[\alpha_{v}\left(y-y^{\prime}\right)\right] \mathrm{d} y^{\prime} \\
& \left.\left.-\alpha_{v} \int_{y}^{\infty} B_{v}\left(y^{\prime}\right) E_{1}\left[\alpha_{v}\left(y^{\prime}-y\right)\right] \mathrm{d} y^{\prime}\right]\right\} \mathrm{d} v
\end{aligned}
$$

where $B_{v}$ denotes the Planck function, $\int_{0}^{\infty} B_{v} \mathrm{~d} v=\sigma T^{4}$, and $E_{n}(t)$ the integro-exponential function of order $n$, defined as $\int_{0}^{1} \mu^{n-2} \mathrm{e}^{-t / \mu} \mathrm{d} \mu$.

Clearly, the foregoing equations for the radiant heat flux are difficult to use because of the complicated nature of $\alpha_{v}(v)$ for real gases. For this reason, and also to obtain results of a general nature rather than those restricted to a single gas, the gray gas approximation $\left(\alpha_{v}=\right.$ constant) has been applied in the past to problems involving gaseous radiation. However, only in the two limiting cases $\alpha_{v} L \rightarrow 0$ (thin gas) and $\alpha_{v} L \rightarrow \infty$ (thick gas) for all $v$, where $L$ denotes a characteristic length, can overall mean absorption coefficients (Planck and Rosseland means, respectively) be defined to correctly account for radiation, and these may differ by orders of magnitude. Yet it is well known from the data available on gases with significant radiation properties (such as carbon dioxide, water vapor and many others) that the optical thickness of the absorbing bands may range from thin to thick, and often assumes intermediate values for which these approximations are not valid. The present work is aimed at improving understanding of this important intermediate optical thickness range by interpolating between thin gas and improved thick gas solutions. 
In order to have a simple approach of general significance and yet to represent the absorption spectrum better than the gray gas approximation, the spectrum is assumed equivalent to a number of bands of arbitrary width and spacing but all of the same height $\alpha_{0}$. The model thus accounts for the windows in the absorption spectra of real gases, and the averaged height $\alpha_{0}$ need account only for strongly absorbing bands. Using this approximation to remove the integro-exponential function from the integration over $v$, and recognizing that by the definition of the Planck mean, $\alpha_{p}$, and modified Planck mean, $\alpha_{M}$, coefficients

$$
\begin{aligned}
& \int_{0}^{\infty} \alpha_{v} B_{v}\left(y^{\prime}\right) \mathrm{d} v=\alpha_{p}(T) \sigma T^{4}\left(y^{\prime}\right), \\
& \int_{0}^{\infty} \alpha_{v} B_{v, w} \mathrm{~d} v=\alpha_{M}\left(T, T_{w}\right) \sigma T_{w}^{4},
\end{aligned}
$$

the integration of equations (5) and (6) over frequency gives

$$
\begin{aligned}
& q^{R}(y)=\epsilon \sigma T_{w}^{4}\left\{1+\frac{\alpha_{M}\left(T, T_{w}\right)}{\alpha_{0}}\left[2 E_{3}\left(\alpha_{0} y\right)-1\right]\right\} \\
& +4 \rho_{w} \sigma E_{3}\left(\alpha_{0} y\right) \int_{0}^{\infty} \alpha_{p}(T) T^{4}\left(y^{\prime}\right) E_{2}\left(\alpha_{0} y^{\prime}\right) \mathrm{d} y^{\prime} \\
& +2 \sigma \int_{0} \alpha_{p}(T) T^{4}\left(y^{\prime}\right) E_{2}\left[\alpha_{0}\left(y-y^{\prime}\right)\right] \mathrm{d} y^{\prime} \\
& -2 \sigma \int_{y}^{\infty} \alpha_{p}(T) T^{4}\left(y^{\prime}\right) E_{2}\left[\alpha_{0}\left(y^{\prime}-y\right)\right] \mathrm{d} y^{\prime}, \quad(9) \\
& \frac{\partial q^{R}}{\partial y}=2 \sigma\left\{2 \alpha_{p}(T) T^{4}(y)-\epsilon \alpha_{M}\left(T, T_{w}\right) T_{w}^{4} E_{2}\left(\alpha_{0} y\right)\right. \\
& -2 \rho_{w} E_{2}\left(\alpha_{0} y\right) \int_{0}^{\infty} \alpha_{p}(T) T^{4}\left(y^{\prime}\right) E_{2}\left(\alpha_{0} y^{\prime}\right) \alpha_{0} \mathrm{~d} y^{\prime} \\
& -\int_{0}^{y} \alpha_{p}(T) T^{4}\left(y^{\prime}\right) E_{1}\left[\alpha_{0}\left(y-y^{\prime}\right)\right] \alpha_{0} \mathrm{~d} y^{\prime}
\end{aligned}
$$

Assuming $\alpha_{v}$ to be independent of temperature, it follows from equations (7) and (8) that

$$
\alpha_{M}\left(T, T_{w}\right)=\alpha_{p}\left(T_{w}\right)
$$

and for a real gas in a limited temperature region the Planck mean coefficient can often be approximated as

$$
\alpha_{p}(T)=\left(T / T_{w}\right)^{m} \alpha_{p}\left(T_{w}\right),
$$

where $m$ depends on the gas and temperature range. For example, for water vapor between between about $1000^{\circ} \mathrm{R}$ and $2500^{\circ} \mathrm{R}, m=-2$ (see [9]). Equations (9) and (10) thus become

$$
q^{R}(y)=\alpha_{p}\left(T_{w}\right) \sigma T_{w}^{4}\left\{\frac{\epsilon}{\alpha_{p}\left(T_{w}\right)}+\frac{\epsilon}{\alpha_{0}}\left[2 E_{3}\left(\alpha_{0} y\right)-1\right]\right.
$$$$
+4 \rho_{w} E_{3}\left(\alpha_{0} y\right) \int_{0}^{\infty} \theta^{4+m}\left(y^{\prime}\right) E_{2}\left(\alpha_{0} y^{\prime}\right) \mathrm{d} y^{\prime}
$$$$
+2 \int_{0}^{x} \theta^{4+m}\left(y^{\prime}\right) E_{2}\left[\alpha_{0}\left(y-y^{\prime}\right)\right] \mathrm{d} y^{\prime}
$$$$
\left.-2 \int_{y}^{\infty} \theta^{4+m}\left(y^{\prime}\right) E_{2}\left[\alpha_{0}\left(y^{\prime}-y\right)\right] \mathrm{d} y^{\prime}\right\},
$$

$$
\frac{\partial q^{R}}{\partial y}=2 \alpha_{p}\left(T_{w}\right) \sigma T_{w}^{4}\left\{2 \theta^{4+m}(y)-\epsilon E_{2}\left(\alpha_{0} y\right)\right.
$$$$
-2 \rho_{w} E_{2}\left(\alpha_{0} y\right) \int_{0}^{\infty} \theta^{4+m}\left(y^{\prime}\right) E_{2}\left(\alpha_{0} y^{\prime}\right) \alpha_{0} \mathrm{~d} y^{\prime}
$$$$
-\int_{0}^{y} \theta^{4+m}\left(y^{\prime}\right) E_{1}\left[\alpha_{0}\left(y-y^{\prime}\right)\right] \alpha_{0} \mathrm{~d} y^{\prime}
$$$$
\left.-\int_{y}^{\infty} \theta^{4+m}\left(y^{\prime}\right) E_{1}\left[\alpha_{0}\left(y^{\prime}-y\right)\right] \alpha_{0} \mathrm{~d} y^{\prime}\right\},
$$

where $\theta=T / T_{w}$.

The term $\epsilon \sigma T_{w}^{4}\left[1-\alpha_{p}\left(T_{w}\right) / \alpha_{0}\right]$ in equation 
(13) represents energy emitted by the wall in bands in which the gas is transparent, and consequently this energy simply passes through the gas until it strikes a bounding surface. In turn, this bounding surface emits and reflects energy back to the wall. However, for the problem being considered here this wall to wall radiant transfer is completely independent of the wall to gas heat transfer, and may consequently be neglected in the following.

It is interesting to note that although the study by Gilles et al. [10] differs considerably from the present one, essentially the same result is obtained for the radiant heat flux.

\section{SELECTION OF TEMPERATURE PROFILES}

Because of the fundamental difference between radiation and conduction, a temperature profile that gives a reasonably accurate result for a transparent gas may not be suitable to an absorbing gas. Consequently careful attention must be paid to profile selection. Clearly, absorption of the major portion of radiation emitted and reflected from the wall in the absorbing bands of the gas occurs in a layer of (transversal) thickness $y$ such that $\alpha_{0} y \approx 1$, so there is always a layer of at least this thickness in which radiant transfer is important. However, since radiant heat transfer cannot force the gas temperature at the wall to equal the wall temperature, a conduction boundary layer also exists. The thickness and temperature of this layer are, of course, affected by radiation, but conduction plays the major role.

Depending upon the size of the governing parameters, the optical thickness, $\tau_{0} \equiv \alpha_{0} \Delta$, of the conduction boundary layer (of thickness $\Delta)$ varies as $0 \leqslant \tau_{0}<\infty$. When $\tau_{0} \ll 1$ the temperature outside the conduction layer may be determined by solving the governing differential equation ignoring conduction, while the temperature inside the conduction layer is affected by both radiation and conduction. When $\tau_{0} \gg 1$, the radiation wall effect is confined to a small fraction of the conduction layer. Away from the wall the rapid decay of the integro-exponential functions makes the radiant transfer essentially dependent on local conditions alone, and thus similar to a diffusion process (Rosseland gas). When $\tau_{0}=O(1)$, both radiation and conduction affect about the same region, so the foregoing simplifications are no longer valid.

The simplest temperature profile that represents the physics, often referred to as the firstorder profile, satisfies the following three conditions :

$$
T(0)=T_{w}, \quad T(\Delta)=T_{\infty}, \quad \frac{\partial T}{\partial y}(\Delta)=0 .
$$

It is well known, however, that for forced convection problems excluding radiation a parabolic profile based on these three conditions, although qualitatively valid, is quantitatively inadequate. At least two methods of improving this profile are commonly employed. One is based on satisfying the differential form of the energy equation and/or its derivatives at one or the other boundary. The second is to satisfy moments of this equation. Since it is not only known to provide a sufficiently accurate answer in the non-radiating case but is also algebraically simpler, the former method is applied here. Specifically, since two of the above conditions apply at $y=\Delta$, the additional condition is obtained by satisfying the differential form of the energy equation at the wall. This gives

$$
\left.k \frac{\partial^{2} T}{\partial y^{2}}\right|_{w}=\left.\frac{\partial q^{R}}{\partial y}\right|_{w} .
$$

Inserting equation (14), equation (15) may be rearranged to give

$$
\begin{aligned}
\left.k \frac{\partial^{2} T}{\partial y^{2}}\right|_{w} & =2 \alpha_{p}\left(T_{w}\right) \sigma T_{w}^{4} \\
\times[2-\epsilon & -2 \rho_{w} \int_{0}^{\infty} \theta^{4+m}\left(y^{\prime}\right) E_{2}\left(\alpha_{0} y^{\prime}\right) \alpha_{0} \mathrm{~d} y^{\prime} \\
& \left.-\int_{0}^{\infty} \theta^{4+m}\left(y^{\prime}\right) E_{1}\left(\alpha_{0} y^{\prime}\right) \alpha_{0} \mathrm{~d} y^{\prime}\right] .
\end{aligned}
$$


For the transparent gas, $\left.\left(\partial^{2} T / \partial y^{2}\right)\right|_{w}$ is zero. As the absorption becomes noticeable, $\left.\left(\partial^{2} T / \partial y^{2}\right)\right|_{w}$ increases correspondingly, bringing in the first order effect of radiation on the temperature distribution. This effect is adequately described by the cubic profile. As absorption continues to increase, the wall effect forces the temperature to take on a rapid change in slope very near the wall, a change the cubic profile is unable to produce. In this case equation (15) may be assumed to hold not only at the wall, but in the neighborhood of the wall, provided $y / \Delta \ll 1$. Outside of this region the cubic profile is still adequate.

\section{THIN GAS ANALYSIS}

Approximation of the radiant heat flux

The problem may be made mathematically tractable by approximating the radiant heat flux. First, the radiant flux to the boundary layer obtained from equation (13),

$$
\begin{gathered}
\left.q^{R}\right|_{w}=2 \sigma \alpha_{p}\left(T_{w}\right) T_{w}^{4}\left\{\left[E_{3}\left(\alpha_{0} \Delta\right)-\frac{1}{2}\right]\right. \\
\times\left[\frac{\epsilon}{\alpha_{0}}+2 \rho_{w} \int_{0}^{\infty} \theta^{4+m}\left(y^{\prime}\right) E_{2}\left(\alpha_{0} y^{\prime}\right) \mathrm{d} y^{\prime}\right] \\
+\int_{0}^{\Delta} \theta^{4+m}\left(y^{\prime}\right) E_{2}\left[\alpha_{0}\left(\Delta-y^{\prime}\right)\right] \mathrm{d} y^{\prime} \\
-\int_{\Delta}^{\infty} \theta^{4+m}\left(y^{\prime}\right) E_{2}\left[\alpha_{0}\left(y^{\prime}-\Delta\right)\right] \mathrm{d} y^{\prime} \\
\left.+\int_{0}^{\infty} \theta^{4+m}\left(y^{\prime}\right) E_{2}\left(\alpha_{0} y^{\prime}\right) \mathrm{d} y^{\prime}\right\}
\end{gathered}
$$

may be simplified for small values of $\tau_{0}$ in the usual manner by noting that

$$
E_{3}\left(\tau_{0}\right)=\frac{1}{2}-\tau_{0}+O\left(\tau_{0}^{2}\right), \quad E_{2}\left(\tau_{0}\right)=1+O\left(\tau_{0}\right),
$$

$\int_{0}^{+o} O\left(\tau_{0}\right) d t=O\left(\tau_{0}^{2}\right)$, and assuming that
$\int_{\Delta}^{\infty} \theta^{4+m}\left(y^{\prime}\right) E_{2}\left(\alpha_{0} y^{\prime}\right) \mathrm{d} y^{\prime}=\theta_{\infty}^{4+m} \int_{\Delta}^{\infty} E_{2}\left(\alpha_{0} y^{\prime}\right) \mathrm{d} y^{\prime}$

The result is

$$
\begin{aligned}
\left.q^{R}\right|_{w} ^{\Delta}=2 \alpha_{p}\left(T_{w}\right) \sigma T_{w}^{4}\left\{2 \int_{0}^{\Delta} \theta^{4+m}\left(y^{\prime}\right) \mathrm{d} y^{\prime}\right. \\
\left.-\Delta\left[\epsilon+\left(1+\rho_{w}\right) \theta_{\infty}^{4+m}\right]\right\} .
\end{aligned}
$$

Furthermore, assuming that

$$
\begin{aligned}
& \int_{0}^{\infty} \theta^{4+m}\left(y^{\prime}\right) E_{2}\left(\alpha_{0} y^{\prime}\right) \alpha_{0} \mathrm{~d} y^{\prime}=\theta_{\infty}^{4+m} \int_{0}^{\infty} E_{2}\left(\alpha_{0} y^{\prime}\right) \alpha_{0} \\
& \int_{0}^{\infty} \theta^{4+m}\left(y^{\prime}\right) E_{1}\left|\alpha_{0}\left(y^{\prime}-y\right)\right| \alpha_{0} \mathrm{~d} y^{\prime} \\
& =\theta_{\infty}^{4+m} \int_{0}^{\infty} E_{1}\left|\alpha_{0}\left(y^{\prime}-y\right)\right| \alpha_{0} \mathrm{~d} y^{\prime},
\end{aligned}
$$

equation (14) becomes

$$
\begin{array}{r}
\frac{\partial q^{R}}{\partial y}=2 \sigma \alpha_{p}\left(T_{w}\right) T_{w}^{4}\left\{2\left[\theta^{4+m}(y)-\theta_{\infty}^{4+m}\right]\right. \\
\left.-\epsilon\left[1-0_{\infty}^{4+m}\right] E_{2}\left(\alpha_{0} y\right)\right\} .
\end{array}
$$

Within the boundary layer $E_{2}\left(\alpha_{0} y\right) \approx 1$, and the expression developed by Cess [1] for this region is a special case of equation (21) for $m=0$.

A two-region study seems convenient for the thin gas analysis.

Region 1. $(\mathrm{y}>\Delta)$. In this region conduction is neglected. When $P<1$, which is usually true for gases and is assumed to be the case here, the thermal boundary layer $\Delta$ is thicker than the hydrodynamic boundary layer $\delta$. Therefore, $u=U_{\infty}, v=0$, and the differential formulation of the problem becomes

$$
\begin{aligned}
\rho C_{p} U_{\infty} \frac{\partial T_{1}}{\partial x}= & -2 \alpha_{p}\left(T_{w}\right) \sigma T_{w}^{4}\left[2\left(\theta_{1}^{4+m}-\theta_{\infty}^{4+m}\right)\right. \\
& \left.-\epsilon\left(1-\theta_{\infty}^{4+m}\right) E_{2}\left(\alpha_{0} y\right)\right] .
\end{aligned}
$$


Introducing

$$
\begin{aligned}
\bar{\theta}^{4+m}(y) & \equiv \frac{\epsilon}{2} E_{2}\left(\alpha_{0} y\right)\left[1-\theta_{\infty}^{4+m}\right]+\theta_{\infty}^{4+m}, \\
B_{\infty} & \equiv \rho U_{\infty} C_{p} T_{w} /(4+m) \sigma T_{w}^{4}, \\
\lambda & \equiv\left(T_{w}-T_{\infty}\right) / T_{w},
\end{aligned}
$$

and using for small $\lambda$ the first two terms of the Taylor series expansion of $\theta^{4+m}$ about $\theta=1$,

$$
\theta^{4+m}=1+(4+m) \theta,
$$

equation (22) may be rearranged to give

$$
\frac{\partial \theta_{1}}{\partial x}=\frac{4 \alpha_{p}\left(T_{w}\right)}{B_{\infty}}\left(\bar{\theta}-\theta_{1}\right),
$$

subject to the boundary condition

$$
\lim _{y \rightarrow \infty} \theta_{1}=\theta_{\infty}=\theta_{1}(0, y) .
$$

This readily yields

$$
\frac{\theta_{1}-\bar{\theta}}{\theta_{\infty}-\theta}=\exp \left[-\frac{4 \alpha_{p}\left(T_{w}\right)}{B_{\infty}}\right] .
$$

Noting that

$$
\begin{aligned}
& \frac{4 \alpha_{p}\left(T_{w}\right)}{B_{\infty}}=\frac{13}{70}\left(\frac{\delta}{\Delta}\right)^{2} \frac{\tau_{0}^{2}}{\mathscr{P}_{w}}, \\
& \mathscr{P}_{w} \equiv \frac{\alpha_{0}^{2} k}{(4+m) \alpha_{p}\left(T_{w}\right) \sigma T_{w}^{3}},
\end{aligned}
$$

where, from the solution to equation (1),

$$
\delta(x)=\sqrt{\left(\frac{280 \mu x}{13 \rho U_{\infty}}\right)},
$$

and restricting the solution to the case where $\tau_{0}^{2} / \mathscr{P}_{w} \ll 1$, an alternate form of equation (27) may be obtained:

$$
\frac{\theta_{1}-\theta_{\infty}}{1-\theta_{\infty}}=-\frac{13 \epsilon}{140 P}\left(\frac{\delta}{\Delta}\right)^{2} \frac{\tau_{0}^{2}}{\mathscr{P}_{w}} E_{2}\left(\alpha_{0} y\right) .
$$

Region 2. $(\mathrm{y}<\Delta)$. Since $\left.\left(\partial q^{R} / \partial y\right)\right|_{w}$ is small, the usual cubic profile

$\frac{\theta_{2}-1}{\theta_{\Delta}-1}=a_{0}+a_{1}(y / \Delta)+a_{2}(y / \Delta)^{2}+a_{3}(y / \Delta)^{3}$

is adequate in this region. Here $\theta_{\Delta} \equiv \theta_{1}(\Delta)$ is obtained from the solution in region 1 . Now the boundary conditions to be satisfied are

$$
\begin{aligned}
& \theta_{2}(0)=1,\left.\quad k \frac{\partial^{2} T_{2}}{\partial y^{2}}\right|_{w} \\
& =2 \sigma \alpha_{p}\left(T_{w}\right) T_{w}^{4}\left(1+\rho_{w}\right)(4+m)\left(1-\theta_{\infty}\right), \\
& \frac{\partial \theta_{2}(\Delta)}{\partial y}=\frac{\partial \theta_{1}(\Delta)}{\partial y}, \quad \theta_{2}(\Delta)=\theta_{1}(\Delta)=\theta_{\Delta},
\end{aligned}
$$

where

$$
\begin{aligned}
\frac{\partial \theta_{1}}{\partial y}(\Delta)=-\frac{13 \epsilon}{140 P} & \frac{\left(1-\theta_{\infty}\right)}{\Delta} \\
& \times\left(\frac{\delta}{\Delta}\right)^{2} \frac{\tau_{0}^{2}}{\mathscr{P}_{w}} \tau_{0} E_{1}\left(\tau_{0}\right) .
\end{aligned}
$$

For small values of $\tau_{0}$ the product $\tau_{0} E_{1}\left(\tau_{0}\right)$ approaches zero, so $\partial \theta_{1}(\Delta) / \partial y \ll \tau_{0}^{2} / \mathscr{P}_{w}$ and is therefore neglected. After solving for the constants, the temperature profile becomes

$$
\begin{aligned}
& \frac{\theta_{2}-1}{\theta_{\Delta}-1}= \frac{1}{2}\left[3+\left(1+\rho_{w}\right) \frac{\tau_{0}^{2}}{\mathscr{P}_{w}}\right]\left(\frac{y}{\Delta}\right) \\
&-\left(1+\rho_{w}\right) \frac{\tau_{0}^{2}}{\mathscr{P}_{w}}\left(\frac{y}{\Delta}\right)^{2} \\
&-\frac{1}{2}\left[1-\left(1+\rho_{w}\right) \frac{\tau_{0}^{2}}{\mathscr{P}_{w}}\right]\left(\frac{y}{\Delta}\right)^{3},
\end{aligned}
$$

or, expressed in terms of $\theta_{\infty}$,

$$
\begin{gathered}
\frac{\theta_{2}-\theta_{\infty}}{1-\theta_{\infty}}=1-\frac{1}{2}\left[3+\frac{\tau_{0}^{2}}{\mathscr{P}_{w}}\left(1+\rho_{w}\right.\right. \\
\left.\left.-\frac{39_{\epsilon}}{140 P} \frac{\delta^{2}}{\Delta^{2}}\right)\right]\left(\frac{y}{\Delta}\right)+\left(1+\rho_{w}\right) \frac{\tau_{0}^{2}}{\mathscr{P}_{w}}\left(\frac{y}{\Delta}\right)^{2} \\
+\frac{1}{2}\left[1-\frac{\tau_{0}^{2}}{\mathscr{P}_{w}}\left(1+\rho_{w}+\frac{13 \epsilon}{140 P} \frac{\delta^{2}}{\Delta^{2}}\right)\right]\left(\frac{y}{\Delta}\right)^{3}
\end{gathered}
$$


Since the solution obtained in region 1 is a solution to the differential energy equation, it readily follows that

$$
\rho C_{p} \frac{\mathrm{d}}{\mathrm{d} x} \int_{\Delta}^{\infty}\left(T-T_{\infty}\right) U_{\infty} \mathrm{d} y=\left.q^{R}\right|_{\Delta} .
$$

Subtracting equation (35) from equation (2), the integral formulation can alternatively be expressed as

$\rho C_{p} \frac{\mathrm{d}}{\mathrm{d} x} \int^{A}\left(T-T_{\infty}\right) u \mathrm{~d} y=\left.q\right|_{w}-\left.q\right|_{\Delta}=-\left.q\right|_{w} ^{A}$.

Defining $\xi \equiv \delta / \Delta$ and noting that

$$
\begin{aligned}
\int_{0}^{\Delta}\left(T-T_{\infty}\right) u \mathrm{~d} y= & \int_{0}^{\delta}\left(T-T_{\infty}\right) u \mathrm{~d} y \\
& +U_{\infty} \int_{\delta}^{\Delta}\left(T-T_{\infty}\right) \mathrm{d} y,
\end{aligned}
$$

the integrals can be evaluated and expressed in terms of $\xi(x)$. The result is

$$
\begin{aligned}
\int_{0}^{4}(T & \left.-T_{\infty}\right) u \mathrm{~d} y=\Delta U_{\infty}\left(T_{w}-T_{\infty}\right)\left\{\frac{3}{8}-\frac{3}{8} \xi\right. \\
+ & \frac{3}{20} \xi^{2}-\frac{\tau_{0}^{2}}{\mathscr{P}_{w}}\left[\left(1+\rho_{w}\right)\left(\frac{1}{24}-\frac{1}{20} \xi^{2}+\frac{1}{24} \xi^{3}\right)\right. \\
& \left.\left.+\frac{13 \epsilon}{140 P}\left(\frac{3}{8} \xi^{2}-\frac{3}{8} \xi^{3}+\frac{3}{20} \xi^{4}\right)\right]\right\} .
\end{aligned}
$$

Inserting the conductive heat flux,

$$
\begin{aligned}
-\left.q^{c}\right|_{w} ^{\Delta}=\left.k \frac{\partial T_{2}}{\partial y}\right|_{w}=\frac{k\left(T_{w}-T_{\infty}\right)}{2 \Delta} & \\
& \times\left[3+\frac{\tau_{0}^{2}}{\mathscr{P}_{w}}\left(1+\rho_{w}-\frac{39_{\epsilon}}{140 P}\right) \xi^{2}\right],
\end{aligned}
$$

and the radiative flux from equation (19),

$$
\begin{array}{r}
-\left.q^{R}\right|_{w} ^{\Delta}=2(4+m) \sigma \alpha_{p}\left(T_{w}\right) T_{w}^{4}\left(1-\theta_{\infty}\right) \\
\times\left(\epsilon-\frac{3}{4}\right) \Delta=2 \frac{k\left(T_{w}-T_{\infty}\right)}{\Delta}\left(\epsilon-\frac{3}{4}\right) \frac{\tau_{0}^{2}}{\mathscr{P}_{w}} .
\end{array}
$$

into equation (36) results in

$$
\begin{aligned}
& \Delta \frac{\mathrm{d}}{\mathrm{d} x} \Delta\left\{\frac{3}{8}-\frac{3}{8} \xi+\frac{3}{20} \xi^{2}-\frac{\tau_{0}{ }^{2}}{\mathscr{P}_{w}}\right. \\
& \times\left[\left(1+\rho_{w}\right)\left(\frac{1}{24}-\frac{1}{20} \xi^{2}+\frac{1}{24} \xi^{3}\right)\right. \\
& \left.\left.+\frac{13 \epsilon}{140 P}\left(\frac{3}{8} \xi^{2}-\frac{3}{8} \xi^{3}+\frac{3}{20} \xi^{4}\right)\right]\right\} \\
& =\frac{k}{2 \rho U_{\infty} C_{p}}\left[3+\frac{\tau_{0}^{2}}{\mathscr{P}_{w}}\right. \\
& \left.\quad \times\left(-1+3 \epsilon-\frac{39_{\epsilon}}{140 P} \xi^{2}\right)\right] .
\end{aligned}
$$

For a non-absorbing gas the solution to equation (41) exists in the literature (see e.g. Eckert and Drake [11]). The result is

$$
\begin{aligned}
1 / \xi(x)= & 1 / \xi_{0}=1 / 2 \\
& +\sqrt{ }(13 / 35 P-3 / 20)=\text { const. }
\end{aligned}
$$

For small values of $\tau_{0}^{2} / \mathscr{P}_{w}$, assume that $\xi(x)$ can be expanded as

$$
\xi(x)=\xi_{0}+\left(\tau_{0}^{2} / \mathscr{P}_{w}\right) \xi_{1}+\ldots
$$

and assume that $\xi_{1}$ is constant as well as $\xi_{0}$.

Carrying out the differentiation, neglecting terms of higher order than $\tau_{0}^{2} / \mathscr{P}_{w}$, and noting that

$$
\delta^{2}(\mathrm{~d} / \mathrm{d} x)\left(\tau_{0}^{2} / \mathscr{P}_{w}\right)=\left(\tau_{0}^{2} / \mathscr{P}_{w}\right)\left(\mathrm{d} \delta^{2} / \mathrm{d} x\right)
$$

yields

$$
\begin{aligned}
& \left\{\frac{3}{8}-\frac{3}{8} \xi_{0}+\frac{3}{20} \xi_{0}^{2}-\frac{\tau_{0}^{2}}{\mathscr{P}_{w}}\left[4 ( \frac { \xi _ { 1 } } { \xi _ { 0 } } ) \left(\frac{3}{8}-\frac{3}{8} \xi_{0}\right.\right.\right. \\
& \left.\quad+\frac{3}{20} \xi_{0}^{2}\right)+3\left(\frac{3}{8} \xi_{1}-\frac{3}{10} \xi_{0} \xi_{1}\right) \\
& +3 \xi_{0}^{2}\left(\frac{39_{\epsilon}}{140 P}\right)\left(\frac{3}{8}-\frac{3}{8} \xi_{0}+\frac{3}{20} \xi_{0}^{2}\right) \\
& \left.\left.+3\left(1+\rho_{w}\right)\left(\frac{1}{24}-\frac{1}{20} \xi_{0}^{2}+\frac{1}{24} \xi_{0}^{3}\right)\right]\right\} \\
& \quad \times \frac{1}{2 \xi_{0}^{2}} \frac{\mathrm{d} d^{2}}{\mathrm{~d} x}=\frac{k}{2 \rho U_{\infty} C_{p}} \\
& \quad \times\left\{3+\frac{\tau_{0}^{2}}{\mathscr{P}_{w}}\left[3 \epsilon\left(1-\frac{13 \xi_{0}^{2}}{140 P}\right)-1\right]\right\} .
\end{aligned}
$$


Equating the coefficients of $\tau_{0}^{2} / \mathscr{P}_{w}$ and solving for $\xi_{1}$ gives

$$
\begin{array}{r}
\left(1+\rho_{w}\right)\left(1 / 16-3 \xi_{0}^{2} / 40+\xi_{0}^{3} / 16\right) \\
+\left(13 \xi_{0}^{2} / 280 P\right)\left[3 \epsilon \left(7 / 8-3 \xi_{0} / 8\right.\right. \\
\left.\left.+3 \xi_{0}^{2} / 20-13 \xi_{0}^{2} / 280 P\right)-1 / 2\right] \\
\hline 3 / 4 \xi_{0}-3 / 16-3 \xi_{0} / 20
\end{array}
$$

which demonstrates the validity of the assumption of a constant $\xi_{1}$ in equation (43).

Finally, the effect of radiation on heat transfer is considered in terms of the Nusselt number. From the definition of the Nusselt number,

$N_{x} \equiv h x / k=\left(\left.q^{\mathcal{C}}\right|_{w}+\left.q^{R}\right|_{w}\right) x / k\left(T_{w}-T_{\infty}\right)$,

where $\left.q^{C}\right|_{w}$ is given by equation (39) and

$$
\left.q^{R}\right|_{w}=\frac{k\left(T_{w}-T_{\infty}\right)}{\Delta}\left(\epsilon \frac{\tau_{0}}{\mathscr{P}_{w}}-\frac{3}{4} \epsilon \frac{\tau_{0}^{2}}{\mathscr{P}_{w}}\right) .
$$

This yields, after dividing through by $R_{x}^{t}$,

$$
\begin{aligned}
\frac{N_{x}}{R_{x}^{t}}=\sqrt{\left(\frac{13}{280}\right) \xi\left[\frac{3}{2}\right.}+\epsilon \frac{\tau_{0}}{\mathscr{P}_{w}} \\
\left.+\frac{\tau_{0}^{2}}{\mathscr{P}_{w}}\left(2-\frac{7}{4} \epsilon-\frac{39 \epsilon}{140 P} \xi_{0}^{2}\right)\right] .
\end{aligned}
$$

The results are plotted and discussed in section VI.

\section{THICK GAS ANALYSIS}

Approximation of the radiant heat flux

The diffusion or Rosseland approximation to the radiant heat flux, obtained by expanding the emissive power in a Taylor series about a point and neglecting higher order terms, has long been recognized to be a valid approximation in an optically thick medium far from boundaries. The result for the radiant heat flux is

$$
q^{R}(y)=-\frac{4 \sigma}{3} \frac{1}{\alpha_{R}} \frac{\mathrm{d} T^{4}}{\mathrm{~d} y}=-\frac{4 \sigma}{3} \frac{T_{w}^{4}}{\alpha_{R}} \frac{\mathrm{d} \theta^{4}}{\mathrm{~d} y},
$$

where $\alpha_{R}$ denotes the Rosseland mean absorption coefficient, defined as

$$
\frac{1}{\alpha_{R}} \equiv \int_{0}^{\infty} \frac{1}{\alpha_{v}} \frac{\mathrm{d} B_{v}}{\mathrm{~d} v} \mathrm{~d} v .
$$

Applying the same procedure to the absorption spectrum used here, the radiant heat flux far from boundaries is found to be

$$
\begin{aligned}
q^{R}(y)=-\frac{4 \sigma}{3} & \frac{1}{\alpha_{0}^{2}} \frac{\mathrm{d}}{\mathrm{d} y}\left[\alpha_{p}(T) T^{4}\right] \\
& =-\frac{4 \sigma}{3} \frac{\alpha_{p}\left(T_{w}\right) T_{w}^{4}}{\alpha_{0}^{2}} \frac{\mathrm{d} \theta^{4+m}}{\mathrm{~d} y} .
\end{aligned}
$$

It follows from (49) and (51) that $\alpha_{0}$ can be evaluated from the Planck and Rosseland mean coefficients. The result is

$$
\alpha_{0}^{2}=\alpha_{R}\left(T_{w}\right) \alpha_{p}\left(T_{w}\right)\left(\frac{4+m}{4}\right) \theta^{m+n},
$$

where it has been assumed that the temperature dependence of $\alpha_{R}$ can be approximated as

$$
\alpha_{R}(T)=\left(T / T_{w}\right)^{n} \alpha_{R}\left(T_{w}\right)
$$

It follows from (52) that $\alpha_{0}$ is constant only if $m+n=0$. However, for $\theta \approx 1, \alpha_{0}$ is approximately constant despite nonzero $m+n$ (For $\theta=1$ and $m=0$, equation (52) is identical to the results of $[10]$ ).

Arpaci and Larsen [12] recently extended the thick gas approximation to include the wall region. Applying their method to the present problem gives

$$
\begin{aligned}
& q^{R}(y)=-\frac{4 \sigma}{3} \frac{\alpha_{p}\left(T_{w}\right) T_{w}^{4}}{\alpha_{n}^{2}} \\
& \quad \times\left[1-\rho_{w} E_{3}\left(\alpha_{0} y\right)-\frac{3}{2} E_{4}\left(\alpha_{0} y\right)\right] \frac{\mathrm{d} \theta^{4+m}}{\mathrm{~d} y} .
\end{aligned}
$$

Approximating the integro-exponential functions by exponentials,

$$
\begin{aligned}
& E_{3}(t) \cong(1 / 2) \exp (-3 t / 2), \\
& E_{4}(t) \cong(1 / 3) \exp (-3 t / 2),
\end{aligned}
$$

the radiant heat flux becomes

$$
\begin{array}{r}
q^{R}(y)=-\frac{4 \sigma}{3} \frac{\alpha_{p}\left(T_{w}\right) T_{w}^{4}}{\alpha_{0}^{2}}\left[1-\left(1-\frac{\epsilon}{2}\right)\right. \\
\left.\quad \times \exp \left(-\frac{3 \alpha_{0} y}{2}\right)\right] \frac{\mathrm{d} \theta^{4+m}}{\mathrm{~d} y} .
\end{array}
$$


A two-region study is also suitable to the thick gas analysis.

Region 1. $(\mathrm{y} \ll \Delta)$. Consider the differential form of the energy equation. If $\tau_{0}$ is very large, the wall effect disappears within a small fraction of the boundary-layer thickness, and in this layer $u, v$, and consequently the left hand side of the energy equation are near zero. It seems reasonable to assume that

$$
0=k \frac{\partial^{2} T_{1}}{\partial y^{2}}-\frac{\partial q^{R}}{\partial y}
$$

subject to the boundary condition $T_{1}(0)=T_{w}$ adequately describes this region. The remaining boundary condition is determined by equating the slope at the outer boundary with that in the adjacent region. Integrating equation (56) once to obtain

$$
k \frac{\partial T_{1}}{\mathrm{~d} y}=q^{R}+c_{1},
$$

substituting $q^{R}$ from equation (55), linearizing the temperature difference, and rearranging, equation (57) becomes

$$
\begin{aligned}
\left\{1+\frac{4}{3 \mathscr{P}_{w}}\right. & {\left[1-\left(1-\frac{\epsilon}{2}\right)\right.} \\
\times & \left.\left.\exp \left(-\frac{3 \alpha_{0} y}{2}\right)\right]\right\} \frac{\partial T_{1}}{\partial y}=\frac{C_{1}}{k} .
\end{aligned}
$$

Integration readily yields

$$
\begin{aligned}
& T_{1}-T_{w}=C_{2} \\
& \times \ln \left\{\frac{3 \mathscr{P}_{w}+4\left[1-(1-\epsilon / 2) \exp \left(-3 \alpha_{0} y / 2\right)\right]}{\left(3 \mathscr{P}_{w}+2 \epsilon\right) \exp \left(-3 \alpha_{0} y / 2\right)}\right\}
\end{aligned}
$$

where $C_{2}=2 \mathscr{P}_{w} C_{1} / \alpha_{0} k\left(3 \mathscr{P}_{w}+4\right)$. It is clear from equation (58) that, for large $\alpha_{0} y$,

$$
\frac{\partial T_{1}}{\partial y} \rightarrow \frac{C_{1}}{k}\left(\frac{1}{1+4 / 3 \mathscr{P}_{w}}\right)=\frac{3}{2} \alpha_{0} C_{2} .
$$

Consequently,

$$
\lim _{\alpha_{0} y \rightarrow \infty}\left(\frac{\partial^{2} T_{1}}{\partial y^{2}}\right)=0
$$

Region 2. $(\mathrm{y}<\Delta)$. In view of the character of the above solution, and in particular equation (61), outside the region of wall influence the profile remains similar to that in a non-absorbing gas. That is,

$$
\frac{T_{2}-T_{\infty}}{T_{w}^{*}-T_{\infty}}=1-\frac{3}{2}\left(\frac{y}{\Delta}\right)+\frac{1}{2}\left(\frac{y}{\Delta}\right)^{3},
$$

where $T_{w}^{*}$ is to be selected so that this profile, which is valid only beyond a certain distance from the wall, matches the solution of region 1 at some value of $y / \Delta$.

The constants $C_{2}$ and $T_{w}^{*}$ are determined by equating temperatures and slopes at a value of $y / \Delta$ such that $y / \Lambda \ll 1$ and $\exp \left[-(3 / 2) \tau_{0}(y / \Delta)\right] \ll 1$. This gives

$C_{2}=-\frac{1}{\tau_{0}} \frac{\left(T_{w}-T_{\infty}\right)}{(1+\beta)}, \quad T_{w}^{*}-T_{\infty}=\frac{T_{w}-T_{\infty}}{1+\beta}$,

where $\beta \equiv\left(1 / \tau_{0}\right)$ ln $\left[\left(3 \mathscr{P}_{w}+4\right) /\left(3 \mathscr{P}_{w}+2 \epsilon\right)\right]$. Thus the profile selection is complete.

Since for $y>\Delta$ it has been assumed that $T_{2}=T_{\infty}$, the integral formulation of the problem given by equation (2) can be rewritten as

$$
\rho C_{p} \frac{\mathrm{d}}{\mathrm{d} x} \int_{0}^{\Delta}\left(T-T_{\infty}\right) u \mathrm{~d} y=\left.q^{C}\right|_{w}+\left.q^{R}\right|_{w},
$$

where

$$
\left.q^{c}\right|_{w}=-\left.\left.k \frac{\partial T_{1}}{\partial y}\right|_{w} \quad q^{R}\right|_{w}=-\left.\frac{8}{3} \epsilon \sigma T_{w}^{3} \frac{\partial T_{1}}{\partial y}\right|_{w} .
$$

Since $u \rightarrow 0$ as $y \rightarrow 0$, it may be assumed that

$$
\begin{aligned}
\int_{0}^{\Delta}\left(T-T_{\infty}\right) u \mathrm{~d} y \cong\left(T_{w}^{*}-T_{\infty}\right) \\
\int_{0}^{4}\left[1-\frac{3}{2}\left(\frac{y}{\Delta}\right)+\frac{1}{2}\left(\frac{y}{\Delta}\right)^{3}\right] u \mathrm{~d} y,
\end{aligned}
$$


which gives

$$
\begin{aligned}
\int_{0}^{\Delta}(T- & \left.T_{\infty}\right) u \mathrm{~d} y=\Delta U_{\infty}\left(T_{w}-T_{\infty}\right) \\
& \times\left(3 / 8-3 \xi / 8+3 \xi^{2} / 20\right) /(1+\beta) .
\end{aligned}
$$

Inserting equation (65) and (67) into (64) yields

$$
\begin{gathered}
\rho C_{p} U_{\infty}\left(\frac{T_{w}-T_{\infty}}{1+\beta}\right) \Delta \frac{\mathrm{d}}{\mathrm{d} x}\left[\Delta\left(\frac{3}{8}-\frac{3}{8} \xi+\frac{3}{20} \xi^{2}\right)\right] \\
=\frac{3}{2} k\left(\frac{T_{w}-T_{\infty}}{1+\beta}\right)\left(1+\frac{4}{3 \mathscr{P}_{w}}\right) .
\end{gathered}
$$

Defining an effective thermal conductivity, $k_{e} \equiv k\left(1+4 / 3 \mathscr{P}_{w}\right)$, to account for both radiation and conduction and an effective Prandtl number based on $k_{e}, P_{e} \equiv \mu C_{p} / k_{e}$, and noting that equation (68) corresponds to the nonabsorbing case except for the replacement of $P$ by $P_{e}$, the solution is seen to be independent of $\tau_{0}$ and is given by

$$
1 / \xi=1 / 2+\sqrt{ }\left(13 / 35 P_{e}-3 / 20\right) .
$$

The Nusselt number, however, depends on $\tau_{0}$, and is given by

$$
\begin{aligned}
N_{x}=\frac{\left.x q\right|_{w}}{k\left(T_{w}-T_{\infty}\right)}= & \frac{3}{2}\left(\frac{1+4 / 3 \mathscr{P}_{w}}{1+\beta}\right) \\
& \times \sqrt{\left(\frac{13 \rho U_{\infty} x}{280 \mu}\right) \xi .}
\end{aligned}
$$

This yields, after dividing through by $R_{x}^{\frac{1}{2}}$,

$$
\begin{aligned}
\frac{N_{x}}{R_{x}^{\frac{1}{2}}}=\frac{3}{2} \sqrt{\left(\frac{13}{280}\right)} & \left(\frac{1+4 / 3 \mathscr{P}_{w}}{1+\beta}\right) /\left[\frac{1}{2}\right. \\
& \left.+\sqrt{ }\left(\frac{13}{35 P_{e}}-\frac{3}{20}\right)\right] .
\end{aligned}
$$

\section{RESULTS AND DISCUSSION}

Due to the number of parameters involved, a complete parametric study of the problem would be rather space consuming. For this reason a few representative values of $\epsilon$ and $\mathscr{P}_{w}$ have been selected for one representative value of the Prandtl number, $P=0 \cdot 74$. Figures 1 and 2

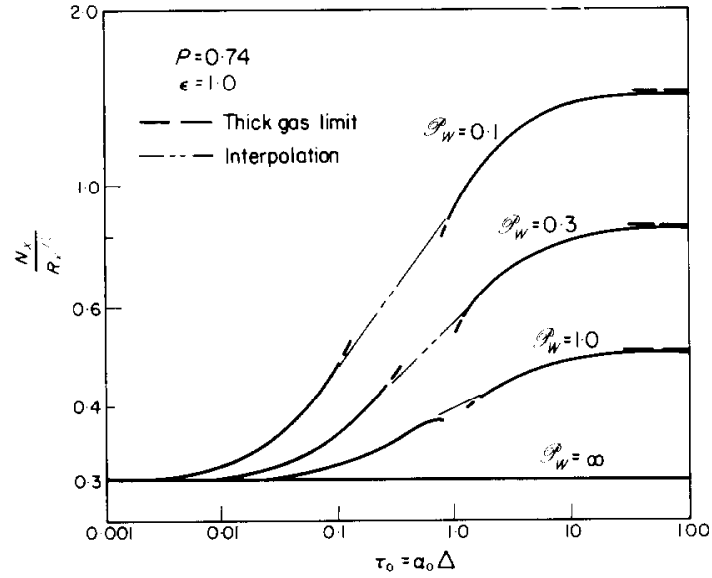

FIG. 1.

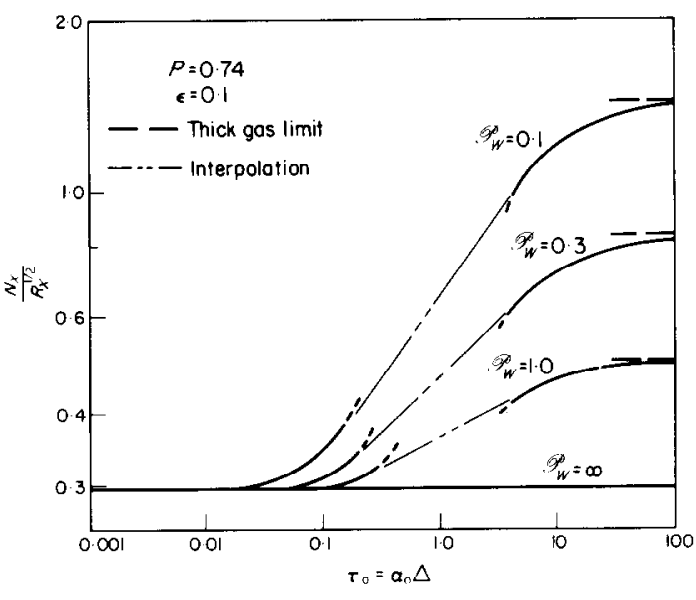

FIG. 2.

illustrate the effect of varying $\tau_{0}$ on $N_{x} / R_{x}^{\frac{1}{2}}$. Figures 3-5 illustrate the temperature profiles for the transparent, thin and thick gas cases.

The Nusselt number results of Figs. 1 and 2 are similar to those of [7], as might be expected. They are also qualitatively quite similar to the results of Viskanta [13] for flow in a parallel plate channel, which apply to all optical thicknesses. An examination of Viskanta's results tends to support the use of an interpolation between the thin and thick gas solutions as a reasonable method of estimating the heat transfer when no solution valid in the intermediate region of optical thicknesses is available. 


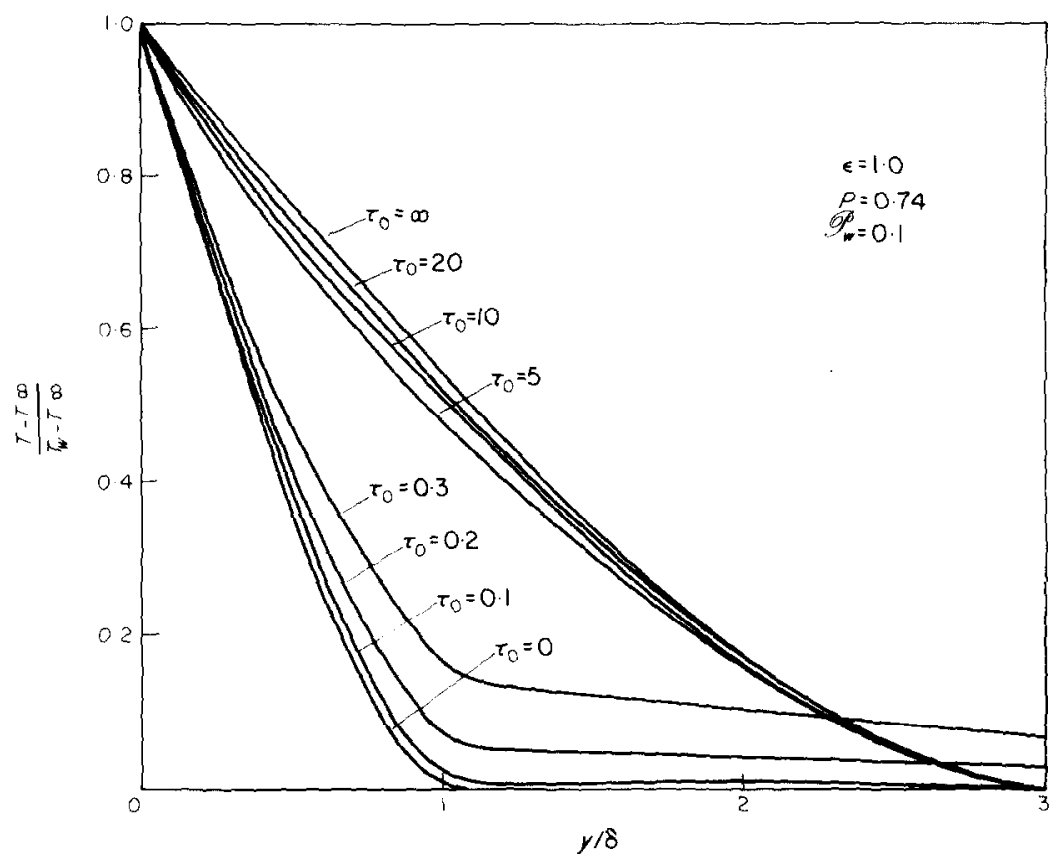

FIG. 3.

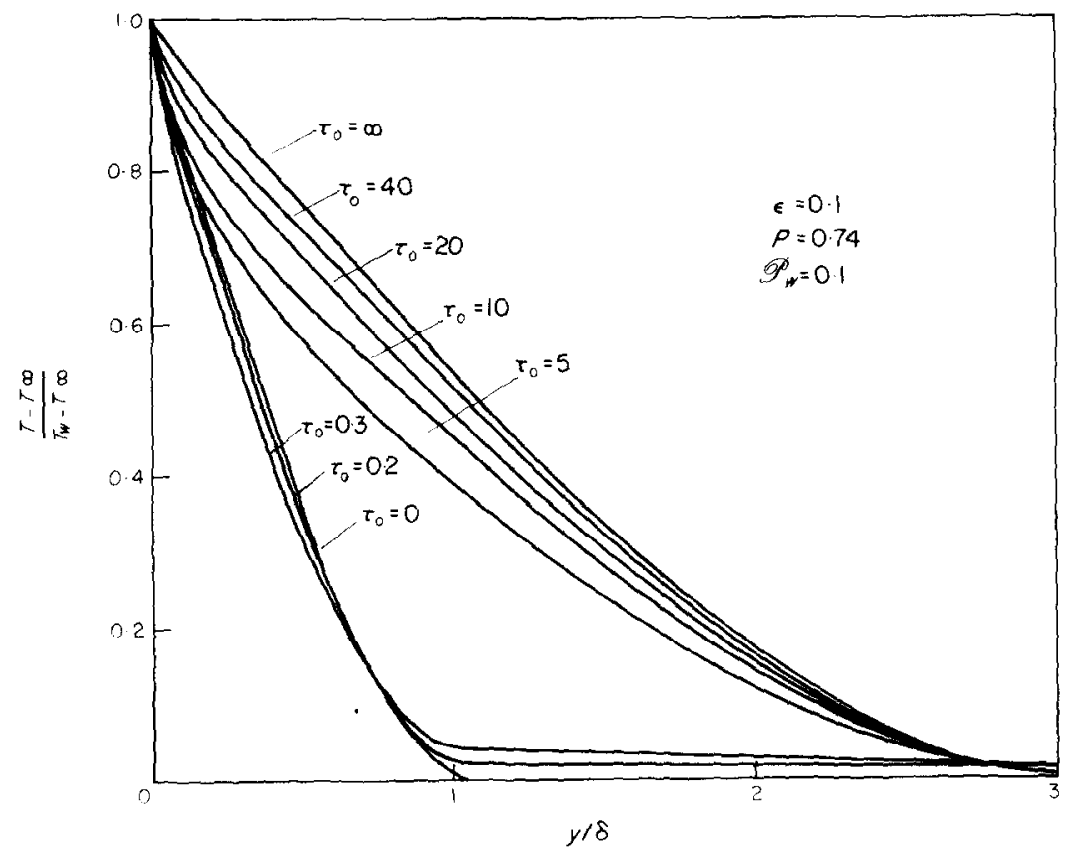

FIG. 4. 


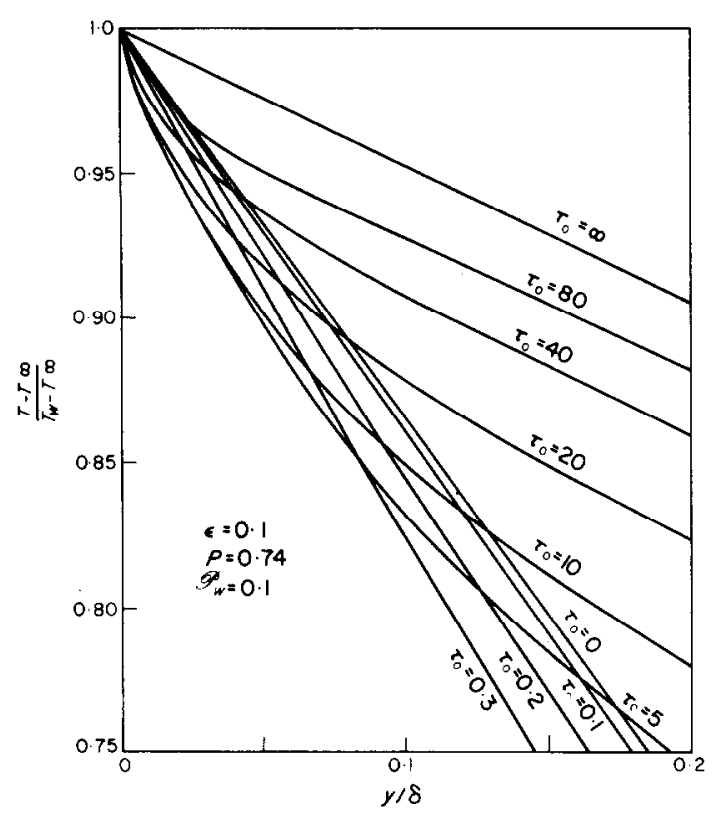

FIG. 5.

In Fig. 6 the results of the present thin gas analysis, restricted here to the gray gas case, are compared with the gray gas results of Cess in [1]. The results of Cess are presented only for $P=1$, while the assumption made in the integral analysis that $\Delta \geqslant \delta$ is valid only for
$P \leqslant 13 / 14$. This slight difference in Prandtl numbers results in a slight discrepancy between the non-radiating solutions, but the effect of absorption of radiation upon the two solutions appears to be very similar.

The behavior of the thick gas solution as $\tau_{0}$ is decreased has not been considered in previous works except for [7] and [12]. Present study predicts a change in slope in this region given by

$$
\frac{\partial T_{1}(0)}{\partial y} / \frac{\partial T_{2}(0)}{\partial y}=\frac{\mathscr{P}_{w}+4 / 3}{\mathscr{P}_{w}+2 \epsilon / 3} .
$$

where $T_{1}$ and $T_{2}$ represent the temperatures in the inner and outer regions, respectively. Novotny and Yang [5] have already shown the special case of the same relation for $\epsilon=1$ by the use of matched asymptotic expansions. Figure 3, for $\epsilon=1$ illustrates the change in temperature profiles as a function of $\tau_{0}$. Figure 4 , for $\epsilon=0 \cdot 1$, illustrates the severe change in the slope of the temperature profiles near the wall. Figure 5 shows the region close to the wall in detail. It should be noted, however, that the expression used for the radiant heat flux in the thick gas is based upon a truncated Taylor series expansion, and therefore excessive curvature in the temperature profile reduces the

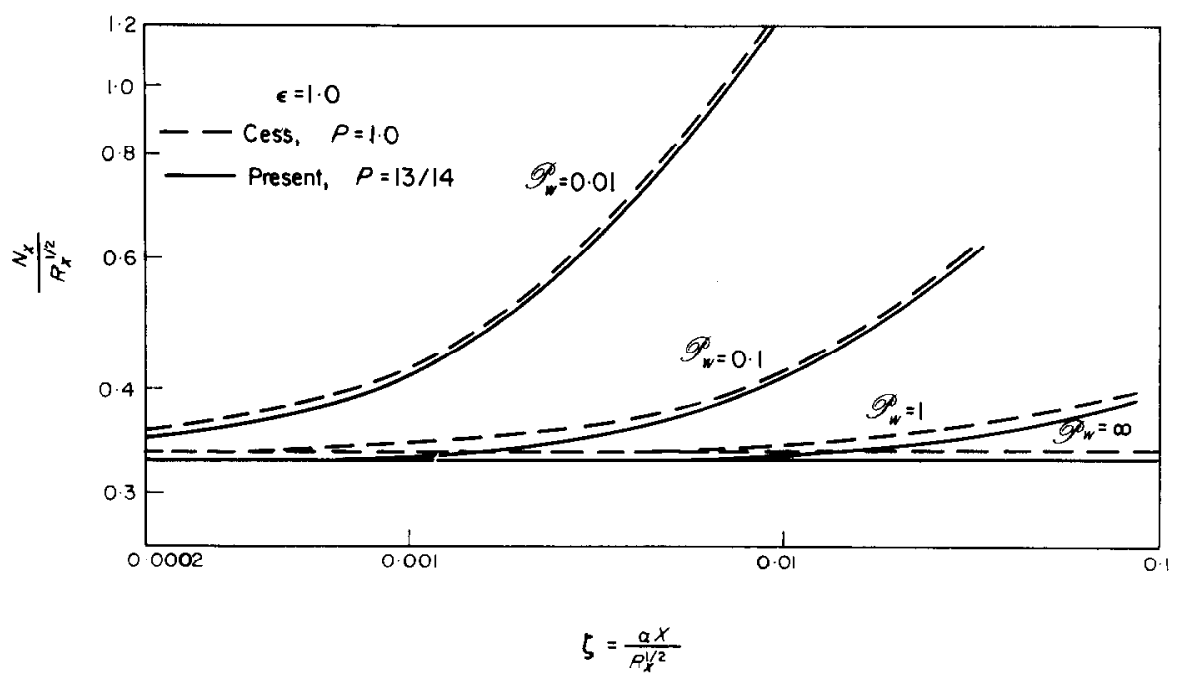

FIG. 6. 
accuracy of the approximation. The selection of $\epsilon=0.1$ is purposely made to dramatize the effect of reducing $\epsilon$, and may possibly be too severe for accurate quantitative results. For details the reader is referred to [12].

\section{REFERENCES}

1. R. D. CESs, Radiation effects upon boundary Jayer flow of an absorbing gas, J. Heat Transfer 86C, 469-475 (1964)

2. C. C. Oliver and P. W. MCFAdDen, The interaction of radiation and convection in the laminar boundary layer, $J$. Heat Transfer 88C, 205-213 (1966).

3. V. P. Zamuraey, Zh. Prikl. Mekhan. i. Tekhn. Fiz. No. 3, 73 (1964).

4. R. Viskanta and R. J. Grosh, Boundary layer in thermal radiation absorbing and emitting media, Int. J. Heat Mass Transfer 5, 795 (1962).

5. J. L. NovotNY and K. T. YANG, The interaction of thermal radiation in optically thick boundary layers, J. Heat Transfer 89C, 309-312, (1967).
6. Y. TAitel and J. P. HartnetT, Equilibrium temperatures in a boundary-layer flow over a flat plate of absorbing-emitting gas, $J$, Heat Transfer 90C, 257-266 (1968).

7. V. S. ARPACI, Effect of thermal radiation on the laminar free convection from a heated vertical plate, Int. J. Heat Mass Transfer 11, 871-881 (1968).

8. L. HowarTh, Modern Development in Fluid Dynamics. Vol. 2. Clarendon Press, Oxford (1953).

9. M. M. ABU- RomiA and C. L. TIEN, Approximate mean absorption coefficients for infrared radiation of gases, J. Heat Transfer 89C, 321 (1967).

10. S. E. Gilles, A. C. Cogley and W. G. Vincenti, A substitute-kernel approximation for radiative transfer in a nongrey gas near equilibrium, with application to radiative acoustics, Int. J. Heat Mass Transfer 12, 445 (1969).

11. E. R. G. Eckert and R. M. DraKe, Heat and Mass Transfer. McGraw-Hill, New York (1959).

12. V. S. ARPACI and P. S. LARSEN, Thick gas near boundaries, AIAA Jl 7, 602 (1969).

13. R. VISKANTA, Interaction of heat transfer by conduction, convection, and radiation in a radiating fluid, $J$. Heat Transfer 85C, 318-328 (1963).

\section{EFFET D'UN RAYONNEMENT THERMIQUE NON GRIS SUR SUR UNE CONVECTION FORCEEE LAMINAIRE POUR UNE PLAQUE HORIZONTALE CHAUFFÉE}

Résumé- On a recherché au moyen d'une méthode intégrale l'interaction du rayonnement et de la convection dans une couche limite absorbante et émétrice. L'écoulement laminaire d'un fluide à propriété constante et non gris sur une plaque plane isotherme, diffusante et grise est considérée pour de petites différences de température. Les analyses de second ordre renfermant l'influence explicite d'un rayonnement sur les profils de tcmpérature sont faites pour des couches limites optiquement fines ou épaisses.

Des solutions sont obtenues en ce qui concerne le nombre de Nusselt et des courbes sont présentées pour illustrer l'effet de l'épaisseur optique sur les profils de température et sur le nombre de Nusselt.

\section{DER EINFIUUSS VON NICHT-GRAUER, THERMISCHER STRAHLUNG AUF DIE LAMINARE, ERZWUNGENE KONVEKTION ÜBER EINE GEHEIZTE HORIZONTALE} PLATTE

Zusammenfassung-Mittels der Integral-Methode wird die Wechselwirkung zwischen Strahlung und Konvektion in einer absorbierenden und emittierenden Grenzschicht untersucht. Dabei wird die laminare Strömung einer nichtgrauen Flüssigkeit konstanter Stoffwerte über eine graue isotherme, ebene Platte für kleine Temperaturdifferenzen betrachtet. Für optisch dünne und dicke Grenzschichten werden Analysen 2. Ordnung ausgeführt, die den expliziten Effekt der Strahlung auf die Temperaturprofile einschliessen. Es ergeben sich Lösungen in geschlossener Form für die Nusseltzahl und Einflüsse der optischen Dicke auf die Temperaturprofile. Die Nusseltzahl wird durch Diagramme erläutert.

\section{ВЛИЯНИЕ НЕСЕРОГО ТЕПЛОВОГО ИЗЛУЧЕНИЯ НА ВЫНУККДЕННУЮ КОНВЕКЦИЮ ПІРИ ЛАМИНАРНОМ ОБТЕКАНИИ НАГРЕТОЙ ГОРИЗОНТАЛЬНОИ ПЛАСТИНЫ}

\footnotetext{
Аннотация-С помощью интегрального метода исследуется изаимодейстиие излучения и конвекции в поглощающем и излучающем пограничном спое. Рассиатриваетя ламинарное обтекание поотоком несерой жидкости с постоянными свойствами серой
} 
рассеиваюцей изотермической пластины при неболыпих разностлх температур. Проведен анализ эффектов второго порядка, в котором в янном виде учтено влиниие излучения на профили температуры для оптиесни тонного и оптичесии толстого пограничных слоев. В замкнутом виде для числа Нуссельта получены реленин.

Представлены графики для иллюстрации влияния оптической толшины на температурные профили и число Нуссельта. 